\title{
Aplikasi Geolistrik Resistivitas dengan Konfigurasi Schlumberger Untuk Identifikasi Air Laut di Kecamatan Jayapura Utara Kota Jayapura
}

\author{
Yogi R P Simanjuntak ${ }^{* 1}$, Tri Budi Prayogo ${ }^{1}$, Moh. Sholichin ${ }^{1}$ \\ ${ }^{1}$ Jurusan Teknik Pengairan Fakultas Teknik Universitas Brawijaya, \\ Jalan Mayjen Haryono No.167, Malang, 65145, INDONESIA \\ *Korespondensi: yz3107@gmail.com
}

\begin{abstract}
In recent years there has been a very large exodus of population increase in the hemisphere, which causes the withdrawal of water from the ground to continue to increase very rapidly. This fact is what makes a very bad impact on the quantity and quality of groundwater, namely a decrease in the level of underground water, as well as very large fluctuations and even a decrease in the quality of underground water, until the consequence is the intrusion of sea water underground in coastal areas. In the framework of this research, we used the geoelectric method to determine the effect of a drop in the underground water level on sea water intrusion in one of the sub-districts in Jayapura City, namely North Jayapura District. North Jayapura We use the geoelectric method to see the effect on the subsidence of the underground water table by the impact of sea water intrusion in the district.
\end{abstract}

Keywords: Geoelectric,Salted Water Intrusion, Schlumberger Configuration Sea Water Level,Resistivity.

Abstrak: Dalam beberapa tahun belakangan telah terjadi eksodus penambahan penduduk yang sangat besar di belahan bumi, yang menyebabkan pengambilan air dalam tanah terus menanjak sangat pesat. Faktor inilah yang membuat dampak sangat jelek terhadap kuantitas dan kualitas air bawah tanah, yaitu turunnya permukaan air bawah tanah, serta fluktuasi yang sangat besar bahkan penurunan kualitas air bawah tanah, sampai terjadinya akibat dari intrusi air laut pada bawah tanah di wilayah pesisir. Dalam rangka penilitian ini, kami memakai metode geolistrik guna mengetahui pengaruh dari penurunan pada muka air bawah tanah terhadap intrusi air laut di salah satu kecamatan di Kota Jayapura yaitu Kecamatan Jayapura Utara. Jayapura Utara Metode dari geolistrik kami gunakan untuk melihat pengaruh pada penurunan muka air bawah tanah oleh dampak dari intrusi air laut di Kecamatan tersebut.

Kata kunci: Intrusi Air Laut, Geolistrik,Kenaikan Muka Air Laut, Konfigurasi Schlumberger, Resistivitas. 


\section{Pendahuluan}

Kita bisa melihat bahwa sangat pentingnya air tanah dalam kehidupan sehari-hari baik dalam kebutuhan konsumsi, untuk keperluan kebutuhan sehari-hari dan keperluan lainnya. Airtanah yang merupakan sumberdaya alam terbarukan menjadi barang ekonomis memiliki peran yang cukup strategis. Menurut [5], Pada saat ini muka airtanah cenderung turun yang berakibat sebagian pompa sumur tidak bisa lagi mengisap air untuk irigasi [4]. Peningkatan eksploitasi airtanah yang sangat pesat di berbagai sektor di Indonesia telah menuntut perlunya persiapan berupa langkah-langkah nyata untuk menanganinya, khususnya memperkecil dampak negatif yang ditimbulkannya.

[8] Beranggapan bahwa kedalaman batas (interface) air tawar dan air asin adalah sekitar 40 kali ketinggian muka air tanah dari muka air laut. Kedalaman bidang temu ini tergantung pada kedudukan paras air tanah tawar yang dihitung dari muka air laut. Air tanah mempunyai tahanan jenis yang lebih rendah daripada batuan mineral. Beberapa penelitian yang terkait dengan pendugaan geolistrik ini diantaranya yaitu penyelidikan untuk mengetahui sebaran mineral batu bara [2].

\section{Bahan dan Metode}

\subsection{Bahan Lokasi Studi}

Studi ini dilakukan di Jayapura kota yang berada di utara Provinsi Papua dengan $1^{\circ} 28^{\prime} 17,26^{\prime \prime} 3^{\circ} 58^{\prime} 0,82^{\prime \prime}$ LS dan $137^{\circ} 34^{\prime} 10,6^{\prime \prime}-141^{\circ} 0$ ' $8,22^{\prime \prime}$ Luas wilayah administrasi kecamatan Jayapura Utara adalah $51,7 \mathrm{~km} 2$.

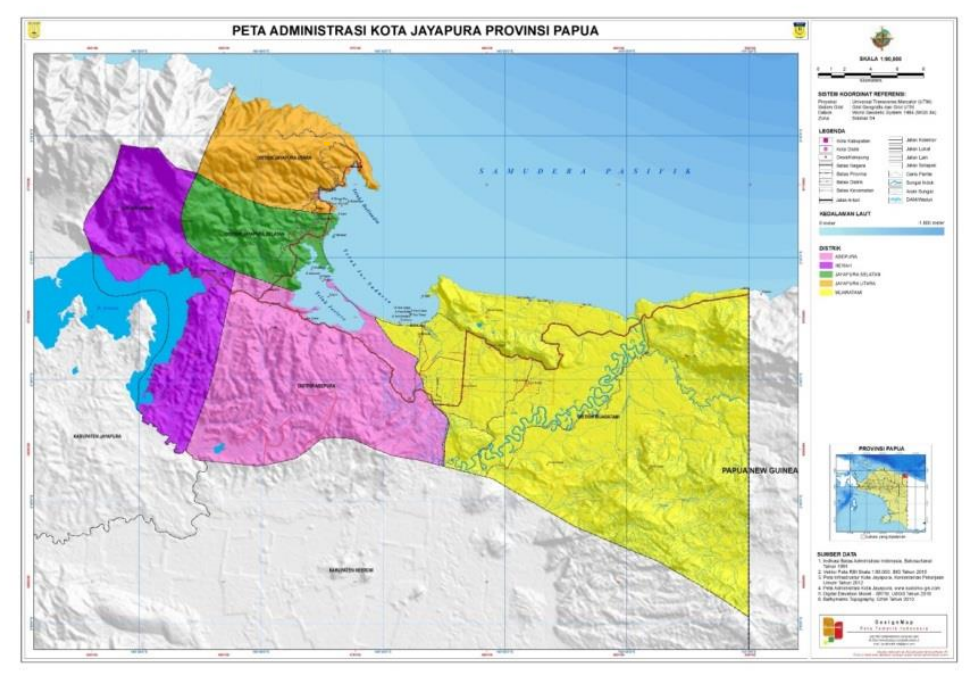

Gambar 1: Lokasi Penelitian Kota Jayapura

\subsubsection{Penelitian Geolistrik}

[3] Beranggapan bahwa pengukuran geolistrik dapat dilakukan dengan tujuan berbeda yaitu pengukuran untuk mapping dan sounding. Pada Penelitian Geolistrik pengambilan data diambil di 4 titik dengan jarak 5-10 meter/section, dengan tiap titik 5 sample berjarak titik pengambilan 5 meter

Berikut Alat-alat yang dipakai untuk penelitian:

- Geolistrick Multichanel (S-Field) 


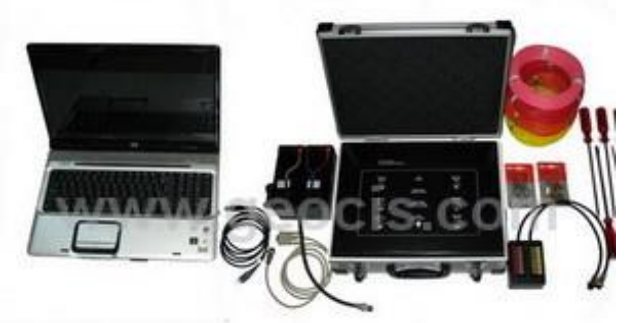

\section{Gambar 2: Resistivitas S-Field 16 Elektroda Automatic Multichanel}

Spesifikasi teknis alat resistivitas S-Field sebagai berikut :

1. High voltage trasmitter

2. Data acquistion

3. PC controller

Keungguan pada alat Geolistrick Multichanneling adalah :

- Pengukurann dapat dilaksanakan dengan otomatis dalam mengambil data sounding dan profiling

- Hasil format output pada file bisa untuk pengolahan memakai res2dinv

- Banyak elektroda dan bisa menaikan standart pada elektroda sampai 1000

- Kekuatas arus 105 MA

- Baterai tahan lama

- Anti circuit short

- Kontrol di lapangan dapat disetting dengan laptop

Akuisisi hasil data geolistik konfigurasi Schlumberger dalam pengambilan hasil data di lapangan dapat dibuat memakai alat geolistrik multichanel antar elektroda dengn jarak $5 \mathrm{~m} / \mathrm{section}$.

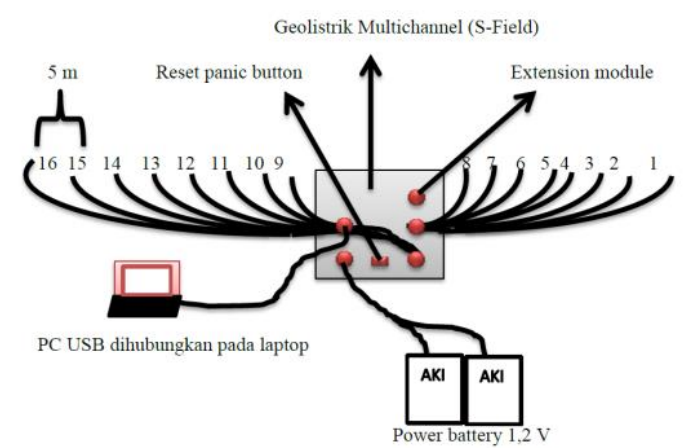

Gambar 3: Skema Susunan Pada Alat Geolistrik Multichennel (S-Field)

Prosedur Penelitian

1. Mengukur panjang dari lintasan

2. Menginjeksi 16 electroda dengan jarak sejauh 5 meter antar elektroda

3. Memasang peralatan kabel pada tiap elektrodae.

4. Kontrol lapangan dengan softaware akuisisi Geores

Berikut adalah hasil dari pengolahan pada excel dari data yang sudah di dapat di lapangan dengan memakai metode konfigurasi schlumberger 
Tabel 1: Data Konfigurasi Schlumberger

\begin{tabular}{|c|c|c|c|c|c|c|}
\hline no & $\begin{array}{c}\mathrm{ab} / 2 \\
(\mathrm{~m})\end{array}$ & $\begin{array}{c}\mathrm{mn} / 2 \\
(\mathrm{~m})\end{array}$ & $\begin{array}{c}\mathrm{i} \\
(\mathrm{mA} .)\end{array}$ & $\begin{array}{c}\mathrm{V} \\
(\mathrm{mV} .)\end{array}$ & $\begin{array}{c}\text { SP } \\
(\mathrm{m} .)\end{array}$ & $\begin{array}{c}\mathrm{K} \\
(\mathrm{mA})\end{array}$ \\
\hline 1 & 0 & 1 & 135 & 1090 & 6,8372 & 8,246 \\
\hline 2 & 5 & 1 & 120 & 155,5 & 6,9021 & 37,699 \\
\hline 3 & 10 & 1 & 87 & 40,4 & 5,7053 & 86,786 \\
\hline 4 & 15 & 1 & 104 & 24 & 5,17176 & 155,510 \\
\hline 5 & 20 & 1 & 85 & 12,6 & 5,89464 & 243,870 \\
\hline 6 & 25 & 1 & 88 & 9,4 & 5,87645 & 351,860 \\
\hline 7 & 30 & 5 & 98 & 32,4 & 6,62035 & 88,957 \\
\hline 8 & 35 & 5 & 82 & 22 & 4,64174 & 117,810 \\
\hline 9 & 40 & 5 & 116 & 25,6 & 5,4055 & 151,190 \\
\hline 10 & 45 & 5 & 140 & 26 & 5,21531 & 188,500 \\
\hline 11 & 50 & 5 & 121 & 19,3 & 2,6565 & 229,730 \\
\hline 12 & 55 & 10 & 135 & 28,3 & 5,48328 & 125,660 \\
\hline 13 & 60 & 10 & 124 & 18,3 & 5,07773 & 176,710 \\
\hline 14 & 65 & 10 & 127 & 13,9 & 7,1909 & 235,620 \\
\hline 15 & 70 & 10 & 125 & 10,2 & 5,88233 & 302,380 \\
\hline 16 & 75 & 15 & 118 & 9,2 & 4,2344 & 238,240 \\
\hline 17 & 80 & 15 & 68 & 5,4 & 5,41287 & 293,220 \\
\hline 18 & 85 & 15 & 68 & 4,9 & 5,3106 & 353,430 \\
\hline 19 & 90 & 15 & 71 & 3,7 & 5,1977 & 418,880 \\
\hline 20 & 95 & 15 & 73 & 3,4 & 4,40295 & 489,560 \\
\hline 21 & 100 & 15 & 60 & 2,5 & 3,9863 & 565,490 \\
\hline 22 & 105 & 20 & 93 & 3,2 & 5,5241 & 471,240 \\
\hline 23 & 110 & 20 & 98 & 4 & 9,6134 & 536,030 \\
\hline 24 & 115 & 20 & 54 & 1,4 & 5,98887 & 604,760 \\
\hline 25 & 120 & 20 & 104 & 3,1 & 4,67008 & 677,410 \\
\hline 26 & 125 & 20 & 66 & 2 & 5,2335 & 753,980 \\
\hline
\end{tabular}

Data yang telat dibuat dalam notepad sesuai format lalu disimpan dengan format data dat dan dibuka melalui aplikasi software RES2dinv.

Cara membuka Res2dinv

1) Klik file pada pojok kiri atas.

2) Pilih read data file

3) Pilih format data (dat) yang tadi sudah di save.

4) Lalu cari inversion.

5) Klik save jika muncul tampilan file name for inersion

\subsubsection{Penelitian Surfer (Pemetaan)}

Data yang di dapat pada excel setelah di render dari :

- Data lokasi dari Google Earth

- Data nomor 1 di konversi ke Gps Visualizer untuk titik koordinatnya

- Konversi data dari Gps Visualizer ke aplikasi TCX Converter agar di convert File tersebut ke excel. Sehingga mendapat angka-angka

- Banyak jenis titik yang di dapat tapi kita hanya memakai data Latitude,longitude dan Altitude pada excel, lalu di masukan pada aplikasi Surver untuk mendapatkan Data Peta Kontur. 


\subsubsection{Bahan Penelitian Teori Serta Cara Pengambilan Sample Air Sumur Penduduk}

Berikut beberapa parameter atau pertimbangan untuk melakukan pengambilan sampe atau sampling data

1. Pemukiman dilewati langsung pada aliran laut.

2. Mempunyai sumur yang dekat dengan air asin atau air laut.

3. Mempunyai sumur yang berada kurang lebih pada kedalaman $30 \mathrm{~m}$

Berikut beberapa ketentuan dalam pengambilan sample atau sampling :

1. Objective, sesuai dengan kenyataan di lapangan.

2. Reprsentative, data mewakili atau menggambarkan keadaan sebenarnya di lokasi.

3. Relefan dan akurat.

4. Mudah di lacak di lapangan.

5. Sample tidak boleh ganda atau data berlebih.

6. Data harus memakai data yang baru.

Prosedur dan bahan atau alat untuk pengambilan sample sebagai berikut:

1. Siapkan beberapa botol mineral yang akan dipakai untuk tempat penyimpanan sampel pada air di sumur..

2. Menyediakan coolbox untuk penyimpanan sampel air sumur.

3. Bilas botol air mineral tadi dengan air sumur yang mau diambil sampelnya.

4. Masukan sampel air ke dalam botol.

5. Alirkan sample secara perlahan agar tidak ada gelembung.

6. Tutup dengan erat botol.

7. Berikan label pada setiap botol yang sudah ada sampelnya.

8. Simpan dan bawa ke lab untuk di uji atau diteliti.

\subsection{Metode}

\subsubsection{Resistivitas}

Resistivitas ditentukan dari suatu tahanan jenis semu yang dihitung dari pengukuran perbedaan potensi antara elektroda yang ditempatkan di dalam bawah permukaan [10].

\subsubsection{Geolistrik}

Geolistrik merupakan sebuah metode yang berfungsi mengetahui aliran sifat listrik dalam bumi dan upaya mendeteksi kebawah perut bumi. Meliputi deteksi beda potensial.beda arus, serta elektrofifamagnetik yang dilakukan dengan penginjeksian ke dalam tanah.

\subsubsection{Konfigurasi Schlumberger}

Konfigurasi schlumberger keempat elektroda disimpan dalam satu baris yang mirip denganWenner tetapi jarak elektroda luar tetap besar dibandingkan dengan jarak elektroda dalam biasanya lebih dari lima kali [6].

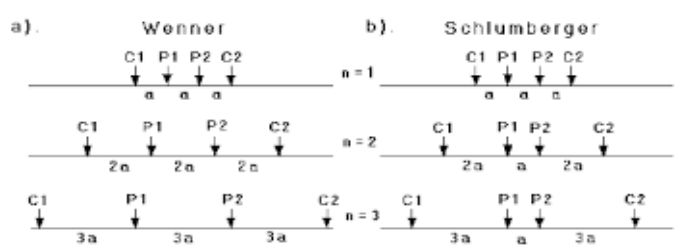

Gambar 4: Ilustrasi Gambar Perbandingan Konfigurasi Wenner Dan Schlumberger 


\subsubsection{Pemetaan Surfer}

Saya menggunakan pemetaan kontur menggunakan pemetaan aplikasi surfer karena bertujuan untuk menghasilkan peta kontur yang di korelasi dengan lokasi studi bertujuan untuk mendapatkan penggambaran yang lebih akurat dan realistis.

Aplikasi pemetaan menggunakan surfer sangat membantu untuk anaisa lereng, lahan dan citra dari satelit yang sudah memiliki data utama ketinggiannya.

\subsubsection{Kualitas Air}

Pada tahapan ini untuk melakukan penelitian kualitas pada air dengan melihat parameter yang ada seperti ph,suhu air, intensitas cahaya, kedalaman, muka air dan catatan hasil pengujiannya [1]. Mengatakan bahwa apabila paras air tanah ini berkurang (karena dipompa airnya), maka akan mengakibatkan kedalaman bidang temu berkurang. Dalam hal ini Bod dan Cod diteliti di laboratorium.

Dalam metode pendugaan bawah permukaan dengan Ground Penetrating Radar (GPR), alat-alat yang digunakan adalah:

- Digital Control Unit GSSI TerraSIRch SIR® System-3000,

- Transmitter dan Receiver GSSI Model 3200 MLF,

- $60 \mathrm{~cm}$ antenna element,

- antenna handle,

- fiber-optic cable,

- baterai $12 \mathrm{~V}$

\subsection{Persamaan}

\subsubsection{Potensial Listrik di Dalam Bumi}

Di dalam bumi terdapat aliran arus listrik. Dan dalam penelitian ini mengukur potensial aliran listrik pada tempat yang diteliti untuk mengetahui intrusi air laut.

Nilai rapat arus $\bar{J}$ dan medan listrik $\bar{E}$ yang ditimbulkan yaitu :

$$
d I=\bar{J} . d A \text { Pers. } 1
$$

Potensial saklar pada medan listrik atau $\mathrm{V}$ :

$$
\bar{J}=\sigma \bar{E} \text { Pers. } 2
$$

$$
\begin{gathered}
\bar{E}=-\bar{\nabla} V \text { Pers. } 3 \\
\bar{J}=-\sigma \bar{\nabla} V \text { Pers. } 4
\end{gathered}
$$

Jika diasumsikan muatannya tetap, maka:

$$
\begin{aligned}
& \int_{A}^{\infty} \bar{J} \cdot d \vec{A}=0 \text { Pers. } 5 \\
& \int_{O}^{\infty} \overline{\nabla . J} d V=0 \text { Pers. } 6
\end{aligned}
$$

Sehingga diperoleh hukum kekekalan muatan :

$$
\begin{aligned}
& \bar{\nabla} \cdot \bar{J}=-\bar{\nabla} \cdot \bar{\nabla}(\sigma \cdot V)=0 \text { Pers. } 7 \\
& -\sigma \bar{\nabla} \cdot \bar{\nabla} V=-\sigma \bar{\nabla}^{2} V=0 \text { Pers. } 8
\end{aligned}
$$

Diperoleh persamaan laplaces karena kondiktifitas dari listrik yang medium dan mempunyai nilai konstan.

$$
\frac{1}{r^{2}} \cdot \frac{\partial}{\partial r}\left(r^{2} \frac{\partial v}{\partial r}\right)+\frac{1}{r^{2} \sin \theta} \cdot \frac{\partial}{\partial \theta}\left(\sin \theta \cdot \frac{\partial v}{\theta}\right)+\frac{1}{r^{2} \sin ^{2} \theta} \cdot \frac{\partial^{2}}{\partial \emptyset^{2}}=0 \text { Pers. } 9
$$

Asumsikan bumi adalah homogen yang isotop dan simetris, jadipada potensil $\mathrm{V}$ adalah $\mathrm{r}$ $(\mathrm{V}=\mathrm{V} . \mathrm{r})$ dari laplaces dengan bentuksimetris bola.

dengan $\mathrm{C}_{1}$ dan $\mathrm{C}_{2}$ adalah konstan

$$
\bar{\nabla}^{2} V=\frac{d}{d r}\left(r^{2} \cdot \frac{d v}{d r}\right)=0 \text { Pers. } 10
$$




\section{Hasil Dan Pembahasan}

Berdasarkan dari penelitian [7], untuk resistivitas antara 1200 - $1700 \Omega$ m merupakan batuan dasar yang tersusun atas lempung, pada lapisan tersebut telah mengandung air asin. Sedangkan harga resistivitas antara 2500 - $4500 \Omega$ m merupakan batuan dasar yang berupa material pasir.

Hasil data dari penelitiaan ini adalah dilaksanakan secara real pada lokasi survey penelitian yang didasarkan dari kuatnya arus listrik dan beda potensial pada lintasan.

3.1. Tahanan Jenis di Kelurahan Imbi (Area Gereja Pengharapan), Kecamatan Jayapura utara, Lokasi studi yang dilakukan di Daerah Kelurahan Imbi berupa 1line

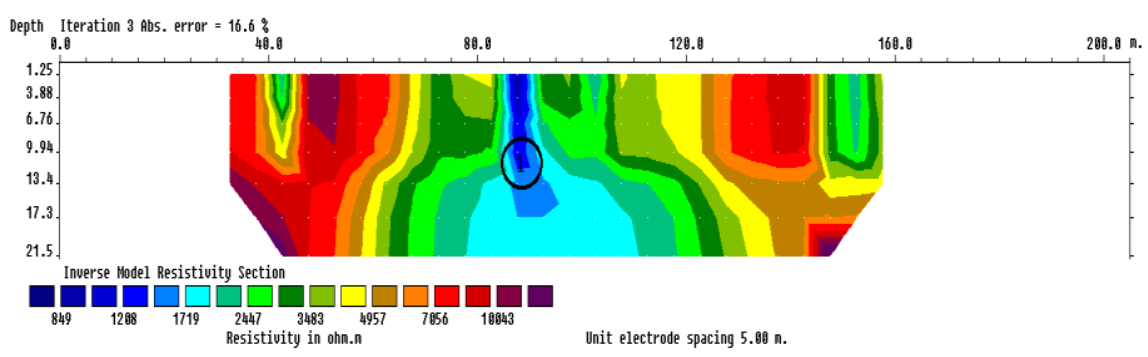

Gambar 5: Penampang Lapisan Bawah Permukaan 2D di Daerah Imbi

Tabel 2 : Analisi Posisi Intrusi Air Laut Line 1

Lokasi Keterangan

1 Pada garis 80-105 m. Dengan resiitivitas $849-1719$ Ohm.m. Letak spot 1 terletak pada kedalaman 13,4-21,5 m didapat potensi dengan dugaan mulai atau sudah terdampak IAL

2 Pada garis kerja 85 - 90 m. Dengan resiitivitas 1500 - 1719 Ohm.m. Letak spot yang sama dengan pertama hanya nilai resisitifitas berbeda tinggi kedalaman 1,25 - $10 \mathrm{~m}$ didapat ptensi dengan dugaan mulai atau sudah terdampak IAL

3.2. Tahanan Jenis di APO, Di Kel APO juga dilakukan penelitian dengan 1 lintasan

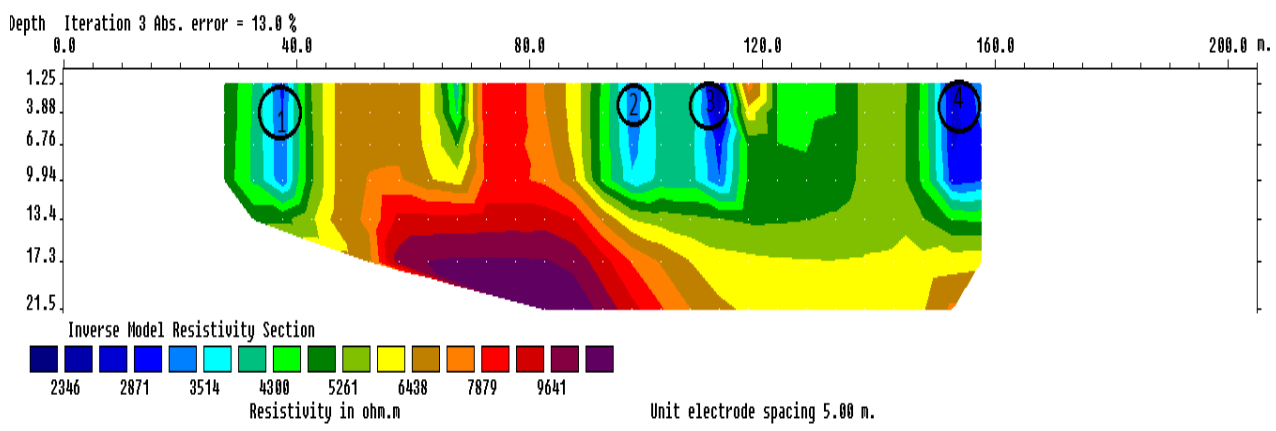

Gambar 6 : Penampang Resistifitas Bawah Permukaan 2D di Daerah kelurahan APO Lintasan 1 


\begin{tabular}{|c|c|}
\hline Lokasi & Keterangan \\
\hline 1 & $\begin{array}{l}\text { Pada garis kerja } 35-40 \mathrm{~m} \text {. Dengan resiitivitas } 2336-3514 \\
\text { Ohm.m. Letak spot } 1 \text { tinggi kedalaman } 1,25-10 \mathrm{~m} \text { didapat ptensi } \\
\text { dengan dugaan mulai atau sudah terdampak IAL }\end{array}$ \\
\hline 2 & $\begin{array}{l}\text { Pada garis kerja } 95-100 \mathrm{~m} \text {. Dengan resiitivitas } 2871-3514 \\
\text { Ohm.m. Letak spot } 2 \text { tinggi kedalaman } 1,25-10 \mathrm{~m} \text { didapat potensi } \\
\text { dengan dugaan mulai atau sudah terdampak IAL }\end{array}$ \\
\hline 3 & $\begin{array}{l}\text { Pada garis kerja } 110-115 \mathrm{~m} \text {. Dengan resiitivitas } 2336-3514 \\
\text { Ohm.m. Letak spot } 3 \text { tinggi kedalaman } 1,25-10 \mathrm{~m} \text { didapat potensi } \\
\text { dengan dugaan mulai atau sudah terdampak IAL }\end{array}$ \\
\hline 4 & $\begin{array}{l}\text { Pada garis kerja } 150-160 \mathrm{~m} \text {. Dengan resiitivitas } 2336-3514 \\
\text { Ohm.m. Letak spot } 4 \text { tinggi kedalaman } 1,25-10 \mathrm{~m} \text { didapat potensi } \\
\text { dengan dugaan mulai atau sudah terdampak IAL }\end{array}$ \\
\hline
\end{tabular}

3.3Tahanan jenis di Dok 4 1-2 line

Line 1

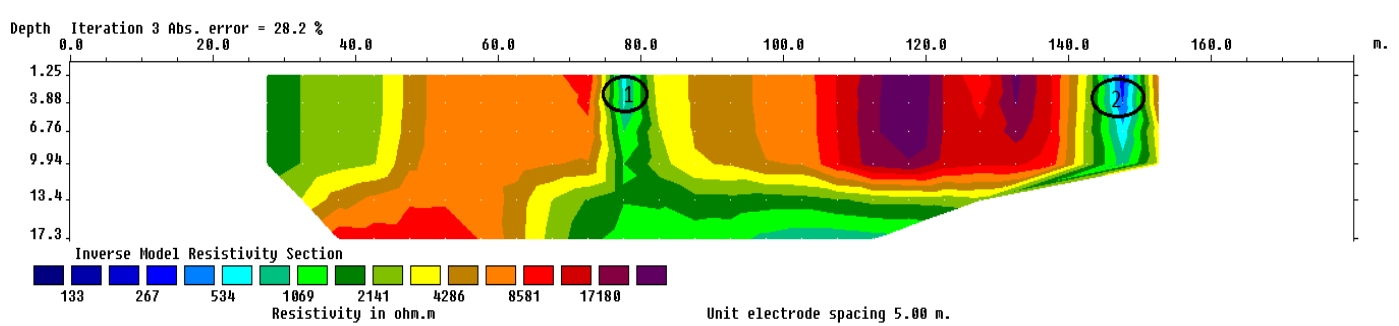

Gambar 7 : Penampang Resistifiti Bawah Permukaan 2D di Dok 4 Lintasan 1

Tabel 4 : Analisa Posisi Intrusi Air Laut Line 1

\begin{tabular}{cl} 
Lokasi & \multicolumn{1}{c}{ Keterangan } \\
\hline 1 & $\begin{array}{l}\text { Pada garis kerja } 75-80 \mathrm{~m} . \text { Dengan resiitivitas } 534-1069 \text { Ohm.m. } \\
\text { Letak spot } 1 \text { tinggi kedalaman } 1,25-6,76 \mathrm{~m} \text { didapat potensi dengan } \\
\text { dugaan mulai atau sudah terdampak IAL }\end{array}$ \\
& $\begin{array}{l}\text { Pada garis kerja } 145-150 \mathrm{~m} . \text { Dengan resiitivitas } 133-534 \text { Ohm.m. } \\
\text { Letak spot } 2 \text { tinggi kedalaman } 1,25-9,94 \mathrm{~m} \text { didapat potensi dengan } \\
\text { dugaan mulai atau sudah terdampak IAL }\end{array}$ \\
&
\end{tabular}

Line 2

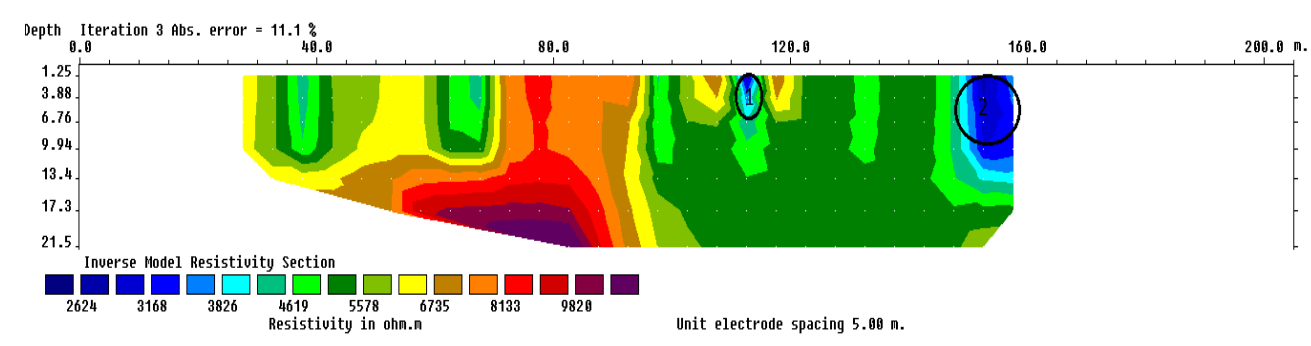


Gambar 8 :Penampang Resistifity Bawah Permukaan 2D di Daerah Dok 4 Lintasan 2

Tabel 5 : Analisa Posisi Intrusi Air Laut Line 2

\begin{tabular}{|c|c|}
\hline Lokasi & Keterangan \\
\hline 1 & $\begin{array}{l}\text { Pada garis kerja } 110-115 \mathrm{~m} \text {. Dengan resiitivitas } 3168-3826 \text { Ohm.m. } \\
\text { Letak spot } 1 \text { tinggi kedalaman } 1,25-6,76 \mathrm{~m} \text { didapat potensi dengan } \\
\text { dugaan mulai atau sudah terdampak IAL. }\end{array}$ \\
\hline 2 & $\begin{array}{l}\text { Pada garis kerja } 150-160 \mathrm{~m} \text {. Dengan resiitivitas } 2624-3826 \text { Ohm.m. } \\
\text { Letak spot } 2 \text { tinggi kedalaman } 1,25-13,4 \mathrm{~m} \text { didapat potensi dengan } \\
\text { dugaan mulai atau sudah terdampak IAL. }\end{array}$ \\
\hline
\end{tabular}

\subsection{Tahanan Jenis di Kelurahan Mandala, Dok 5}

Pada kondisi di Mandala Dok 5, ternyata masih sangat memungkinkan memakai 2 bentang atau 2 line. Panjang antar lintasan adalah $100 \mathrm{~m}$ dan jarak elektroda adalah 5 meter. Berikut data yang telat di dapat menggunakan res2dinv.

Line 1

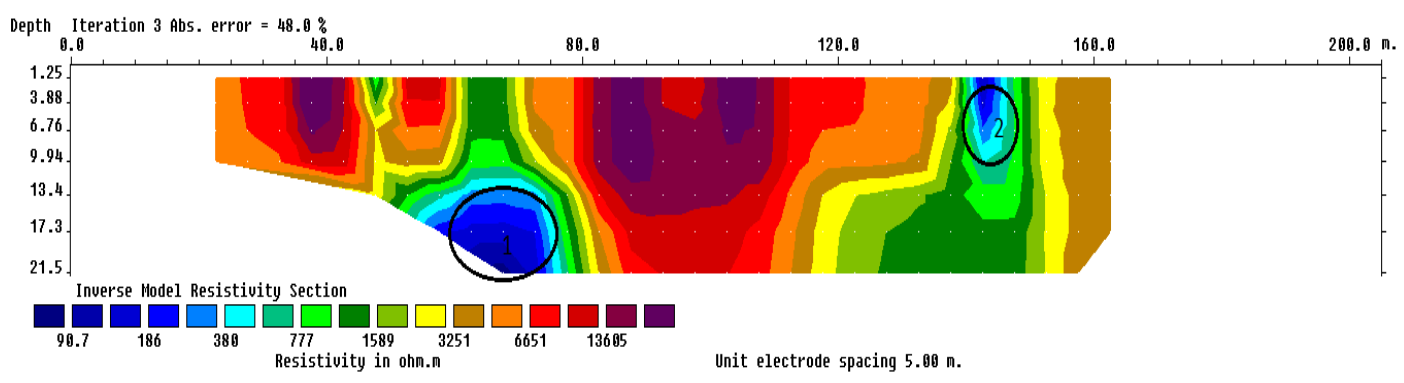

Gambar 9 : Penampang Pada Bawah Permukaan 2D di Daerah Mandala,Dok 5 Lintasan 1

Tabel 6 : Analisa Posisi Intrusi Air Laut

\begin{tabular}{cl}
\hline Lokasi & \multicolumn{1}{c}{ Keterangan } \\
\hline 1 & $\begin{array}{l}\text { Pada garis kerja 55-75 m. Dengan resiitivitas 90,7-380 Ohm.m. Letak } \\
\text { spot 1 tinggi kedalaman 9,94-21,5 m didapat potensi dengan dugaan } \\
\text { mulai atau sudah terdampak IAL } .\end{array}$ \\
& $\begin{array}{l}\text { Pada garis kerja 140-145 m. Dengan resiitivitas 186-777 Ohm.m. } \\
\text { Letak spot 2 tinggi kedalaman 1,25-9,94 m didapat potensi dengan } \\
\text { dugaan mulai atau sudah terdampak IAL }\end{array}$ \\
\hline
\end{tabular}

Line 2

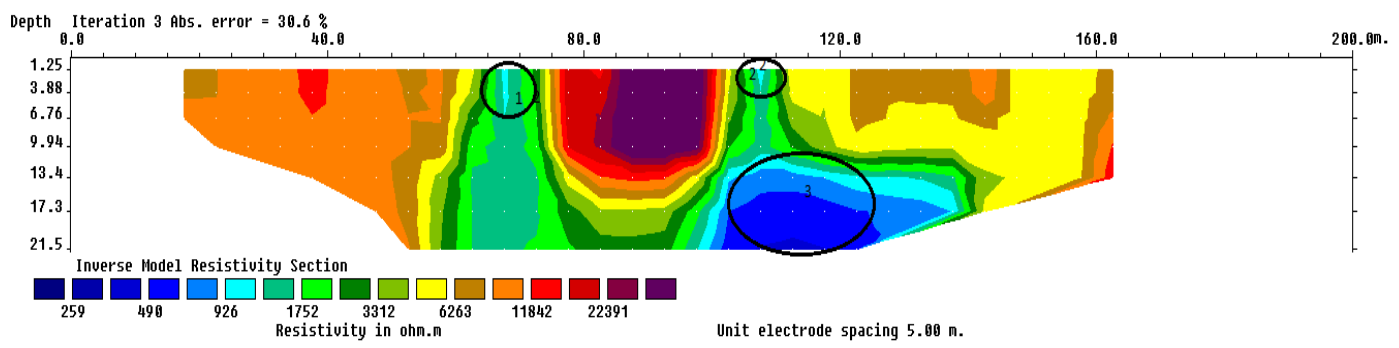

Gambar 10: Penampang Pada Permukaan 2-D di Daerah Mandala,Dok 5 Lintasan 2 
Tabel 7 : Analisa Posisi Intrusi Air Laut Line 2

\begin{tabular}{cl}
\hline Lokasi & \multicolumn{1}{c}{ Keterangan } \\
\hline \multirow{2}{*}{1} & $\begin{array}{l}\text { Pada garis kerja 65-70 m. Dengan resiitivitas 926-1752 Ohm.m. Letak } \\
\text { spot } 2 \text { tinggi kedalaman 1,25-6,76 m didapat potensi dengan dugaan } \\
\text { mulai atau sudah terdampak IAL. }\end{array}$ \\
& $\begin{array}{l}\text { Pada garis kerja 105-110m. Dengan resiitivitas } 926-1752 \text { Ohm.m. } \\
\text { Letak spot 2 tinggi kedalaman 1,25-6,76 m didapat potensi dengan } \\
\text { dugaan mulai atau sudah terdampak IAL . }\end{array}$ \\
& Pada garis kerja 100-140 m. Dengan resiitivitas 259-926 Ohm.m. Letak \\
& spot 3 tinggi kedalaman 9,94-21,5 m didapat potensi dengan dugaan \\
& mulai atau sudah terdampak IAL.
\end{tabular}

\subsection{Pemetaan Menggunakan Surver}

Penggambaran peta kontur bertujuan untuk menghasilkan peta kontur yang di korelasi dengan aplikasi surfer pada lokasi studi bertujuan untuk mendapatkan hasil yang menguatkan data primer

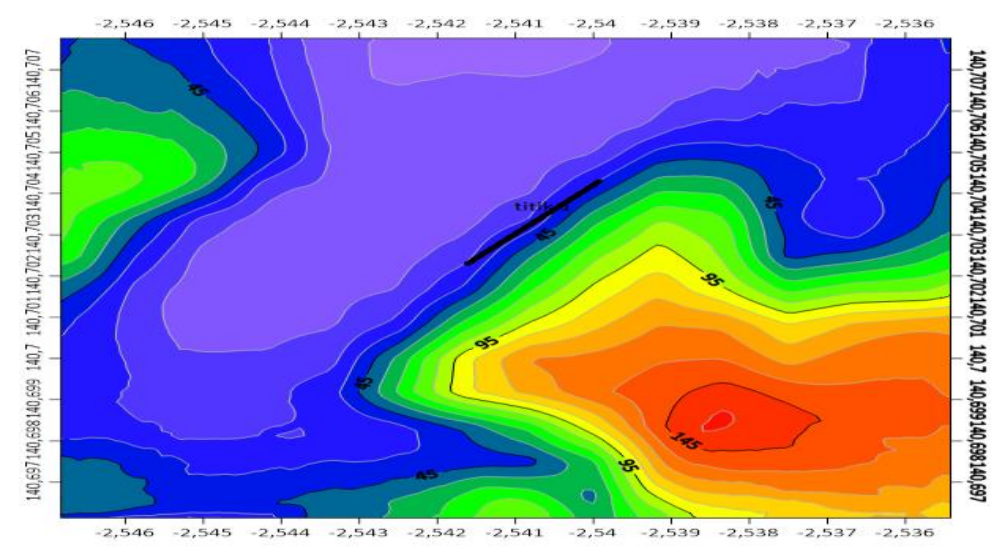

Gambar 11: Hasil Penggambaran Peta Lokasi Menggunakan Aplikasi Surfer Imbi

Angka 140,7 Sumbu X Lat, angka -2,546 sumbu Y longitude serta sumbu Z adalah altitude.area yang terindikasi intrusi air laut berada di titik sebaran elevasi atau altitude 550' atau yang berwarna biru. memiliki Interval Kontur (CI) 15.berada pada skala: CI x $2000=15 \times 2000=30.000$ skala peta $1: 30.000 \mathrm{Jarak}$ garis kontur lokasi pada ketinggian $15-35 \mathrm{mdpl}$ 


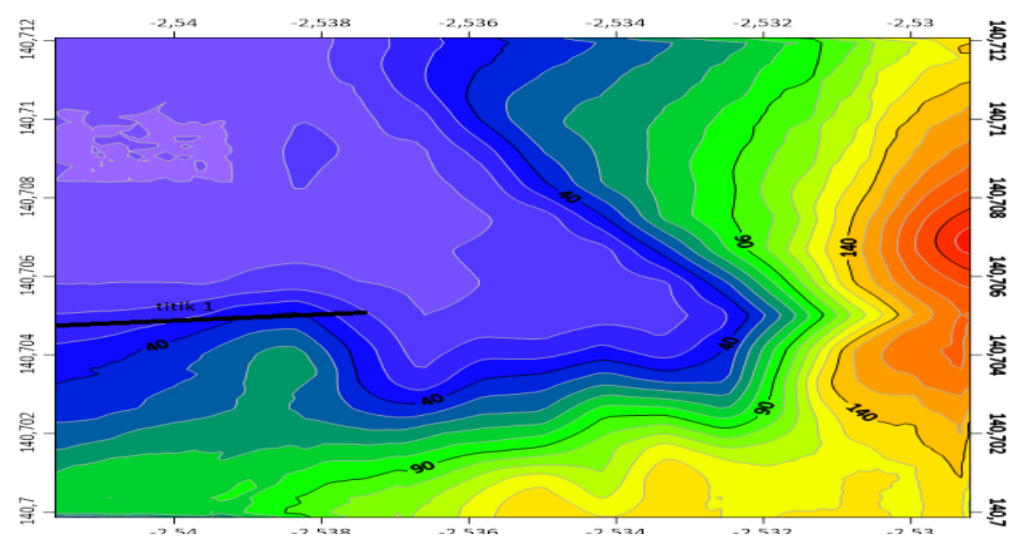

Gambar 12: Hasil Penggambaran Peta Lokasi Menggunakan Aplikasi Surfer Apo

Angka 140,7 Sumbu X Lat, angka -2,546 sumbu Y longitude serta sumbu Z yang adalah altitude.area yang terindikasi intrusi air laut berada di titik sebaran elevasi atau altitude 5-50' atau yang berwarna biru. memiliki Interval Kontur (CI)

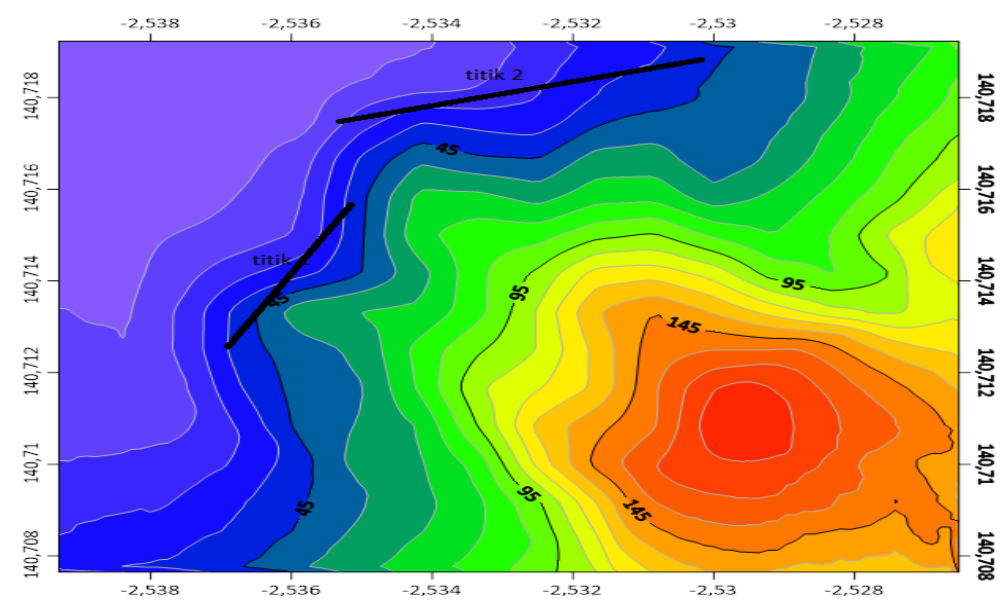

\section{Gambar 13: Hasil Penggambaran Peta Lokasi Menggunakan Aplikasi Surfer Dok IV}

Angka 140,7 Sumbu X Lat, angka -2,546 sumbu Y longitude serta sumbu Z yang adalah altitude.area yang terindikasi intrusi air laut berada di titik sebaran elevasi atau altitude 5-50' atau yang berwarna biru. memiliki Interval Kontur (CI) 15.berada pada skala: CI x $2000=15$ x $2000=30.000$ skala peta $1: 30.000$ Jarak garis kontur lokasi pada ketinggian 15-35 mdpl 


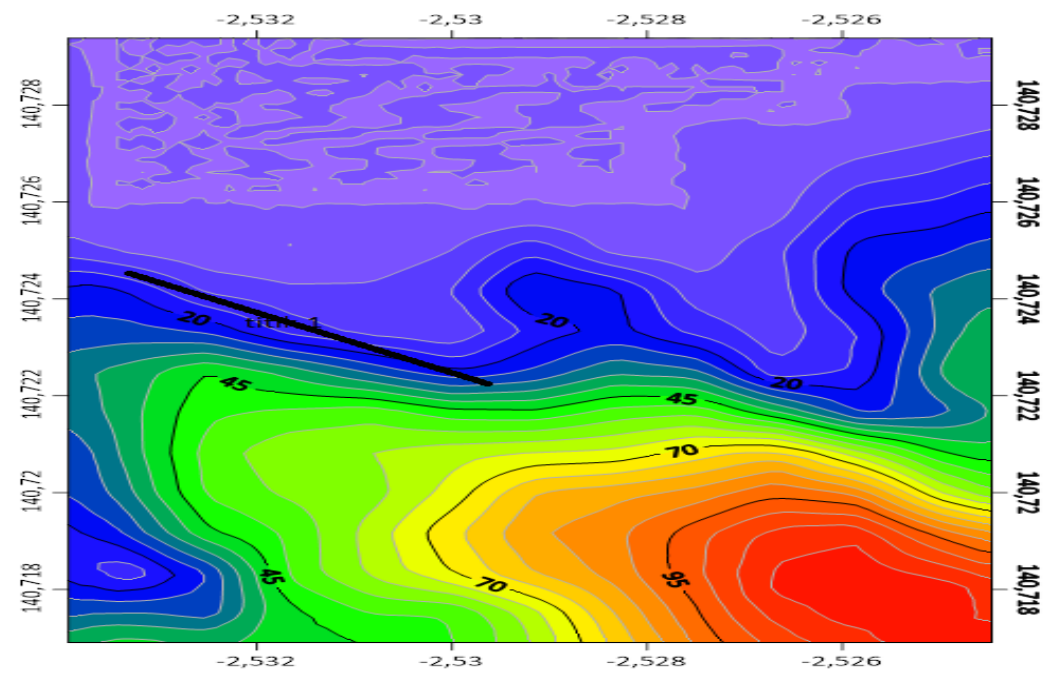

\section{Gambar 14: Hasil Penggambaran Peta Lokasi Menggunakan Aplikasi Surfer Mandala}

Angka 140,7 Sumbu X Lat, angka -2,546 sumbu Y longitude serta sumbu Z yang adalah altitude.area yang terindikasi intrusi air laut berada di titik sebaran elevasi atau altitude 5-50' atau yang berwarna biru. memiliki Interval Kontur (CI) 15.berada pada skala: CI $\times 2000=15 \times 2000=30.000$ skala peta $1: 30.000$ Jarak garis kontur lokasi pada ketinggian 15-35 mdpl

\subsection{Analisis kimiawi airtanah Dok IV}

Menurut [9], intrusi air laut merupakan fenomena yang sering terjadi pada akuiferakuifer pesisir. Secara umum, fenomena ini dapat terjadi ketika muka air tanah pada akuifer air tawar lebih rendah dibandingkan permukaan air laut rata-rata, sehingga mengakibatkan air laut mendesak air tawar kearah darat.

Berikut analisis kimiawi airtanah di Dok IV telah dilakukan oleh Dinas Lingkungan Hidup Kota Jayapura. Pemeriksaan dilakukan di Balai Laboratorium Kesehatan Daerah Papua yang meliputi pengujian parameter standar air minum. Hasil penelitian tersebut terlampir. Pada table dibawah ini, hanya digambarkan beberapa parameter yang mengalami perubahan berdasarkan hasil uji air minum

Tabel 8 : Hasil Uji Air Minum dan Sanitasi Lingkungan

\begin{tabular}{|c|c|c|c|c|c|c|c|c|}
\hline No & Parameter & Satuan & \multirow{2}{*}{$\begin{array}{c}\text { Baku } \\
\text { Mutu }\end{array}$} & & \multicolumn{7}{|c|}{ Hasil Uji } \\
\cline { 5 - 9 } & & & & 1 & 2 & 3 & 4 & 5 \\
\hline 1 & TDS & $\mathrm{mg} / \mathrm{l}$ & 500 & 770.0 & 191.0 & 277.0 & 171.0 & 884.0 \\
\hline 2 & $\begin{array}{c}\text { Kesadahan } \\
\text { Total (CaCO3) }\end{array}$ & $\mathrm{mg} / \mathrm{l}$ & 500 & 508.0 & 231.0 & 246.0 & 185.0 & 650.0 \\
\hline 3 & Besi (Fe) & $\mathrm{mg} / \mathrm{l}$ & 0.3 & 0.210 & 0.030 & 0.020 & 0.76 & 0.07 \\
\hline 4 & Timbal (Pb) & $\mathrm{mg} / \mathrm{l}$ & 0.01 & 0.038 & 0.026 & 0.021 & 0.022 & 0.037 \\
\hline 5 & Coli Tinja & $\begin{array}{c}\text { MPN/ } \\
100 \mathrm{ml}\end{array}$ & 0 & 2 & 0 & 0 & 0 & 0 \\
\hline 6 & Coliform & $\begin{array}{c}\text { MPN/ } \\
100 \mathrm{ml}\end{array}$ & 0 & 27 & 8 & 5 & 9 & 17 \\
\hline
\end{tabular}


Tabel 9 : Uji Nilai DHL,Elevasi,Kedalaman dan Muka Air

\begin{tabular}{|c|c|c|c|c|c|}
\hline No & Nama Pengelola & $\begin{array}{l}\text { Nilai DHL } \\
\text { (mhas/cm) }\end{array}$ & $\begin{array}{c}\text { Elevasi } \\
(\mathrm{mdpl})\end{array}$ & $\begin{array}{l}\text { Kedalaman } \\
\text { (m) }\end{array}$ & $\begin{array}{l}\text { MA } \\
\text { (m) }\end{array}$ \\
\hline 1 & Alm. Yanto Bonai & 594 & 5 & 15 & $\begin{array}{c}3.0 \\
5 \\
3.0\end{array}$ \\
\hline 2 & Edi Ismail & 402 & 5 & 16 & $\begin{array}{c}0 \\
1.8\end{array}$ \\
\hline 3 & Jhon Sikora & 2500 & 4 & 12 & $\begin{array}{c}0 \\
2.5\end{array}$ \\
\hline 4 & Sumur Pantau & 2740 & 4 & 16 & $\begin{array}{c}6 \\
2.6\end{array}$ \\
\hline 5 & Kantor & 1173 & 4 & 24 & $\begin{array}{c}0 \\
2.7\end{array}$ \\
\hline 6 & Alwi Hidayat & 663 & 4 & 16 & $\begin{array}{c}0 \\
2.8\end{array}$ \\
\hline 7 & Ginting & 560 & 4 & 18 & $\begin{array}{c}0 \\
2.3\end{array}$ \\
\hline 8 & Galangan Kapal & 2270 & 2 & 4 & 0 \\
\hline
\end{tabular}

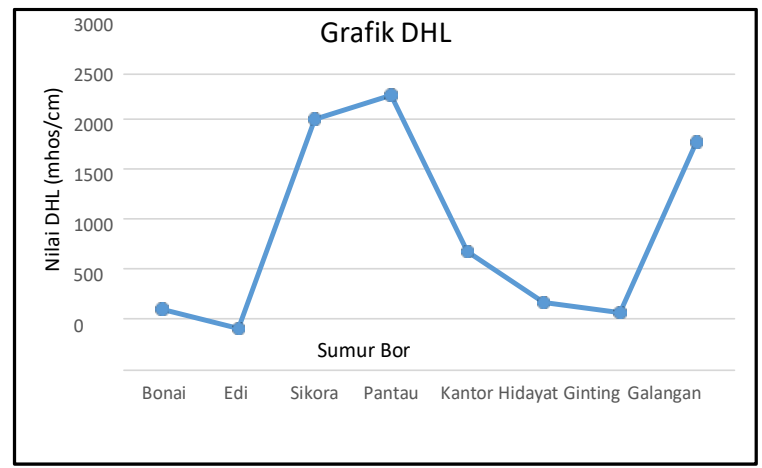

Gambar 15: Grafik DHL Pada Sumur Bor

\section{Kesimpulan}

Dari analisa berikut diperoleh hasil:

- Nilai Resistivitas dan Kedalaman Pada Daerah Yang Diperkirakan Terdampak Intrusi Pada Daerah Imbi berada di Titik 1 dengan nilai resistivitas 849 - $1208 \Omega \mathrm{m}$ Pada Kedalaman 13,4-21,5 m dan pada Titik 21500 - $1719 \Omega \mathrm{m}$ di dalam kedalamann 1,25-10 m.

Nilai Resistivitas \& Kedalaman Pada Daerah Yang Diperkirakan Terdampak Intrusi Pada Daerah Apo berada di titik 1 dengan nilai resistivitas 2340 - $2871 \Omega \mathrm{m}$ di dalam kedalamann 1,25-9,94 m dan pada Titik 2 nilai resistivitas 2871 - 3514 $\Omega \mathrm{m}$ di dalam kedalaman 1,25-9,94 m dan pada Titik 3 nilai resistivitas 2336 $3514 \Omega \mathrm{m}$ dalam kedalamann1,25-9,94 $\mathrm{m}$, serta pada Titik 4 dengan nilai resistivitas 2336 - $3514 \Omega \mathrm{m}$ di dalam kedalaman 1,25-13,4 m

Nilai Resistivitas dan Kedalaman Pada Daerah Yang Diperkirakan Terdampak Intrusi di Daerah Dok IV line 1 berada di Titik 1 dengan nilai resistivitas 534 $1069 \Omega \mathrm{m}$ di dalam kedalamann 1,25-6,76 m serta pada Titik 2 dengan nilai resistivitas $133-267 \Omega \mathrm{m}$ di dalam kedalamann 1,25- 9,94 m

Daerah Dok IV line 2 berada di Titik 1 dengan nilai resistivitas $3168-3826 \Omega \mathrm{m}$ di dalam kedalaman 1,25-6,76 m dan pada Titik 2 nilai resistivitas 2624 - $3826 \Omega \mathrm{m}$ dalam kedalamann 1,25-13,4 m 
Nilai Resistivitas dan Kedalaman Pada Daerah Yang Diperkirakan Terdampak Intrusi pada Daerah Mandala line 1 berada di Titik 1dengan nilai resistivitas 90,7 - $380 \Omega \mathrm{m}$ di dalam kedalamann 9,94-21,5 m. serta pada Titik 2 dengan nilai resistivitas 186- $777 \Omega \mathrm{m}$ di dalam kedalamann 1,25-9,94 m. Daerah Mandala line 2 pada Titik 1 dengan nilai resistivitas $926-1752 \Omega \mathrm{m}$ di dalam kedalaman 1,25$6,76 \mathrm{~m}$, pada Titik 2 nilai resistivitas $926-1752 \Omega \mathrm{m}$ di dalam kedalamann 1,25 $3,88 \mathrm{~m}$, dan pada Titik 3 dengan nilai resistivitas $259-926 \Omega \mathrm{m}$ di dalam kedalaman 9,94-21,5 m.

- Jenis lapisan dan akuifer pada lokasi skripsi disusun beberapa lapisan yaitu bebatuan pasir, batuan lempung, beberapa endapan yang tercampur sdimentnya lapisan bebatuan lempung dan pasir serta lapisan payau. Melihat dari kondisi morfologinya pada daerah penelitian dan berdasarkan penyusunnya jenis akuifer pada daerah penelitian merupakan akuifer bebas dan akuifer tertekan

- Di beberapa wilayah kecamatan Jayapura utara ini pada tiap daerahnya yaitu wilayah distrik Imbi, Apo, Dok 4 serta Mandala diperkirakan mulai terdampak intrusi rata-rata pada kedalaman 9-21 meter. Untuk daerah yang terdampak paling banyak terdapat di wilayah Apo.

- Melihat beberapa parameter yang melebihi baku mutu satandar air minum pada hasil uji laboratorium, menggambarkan bahwa air tanah di Dok IV yang dalam penelitian ini mewakili sebagian wilayah Jayapura utara telah mengalami pencemaran dan salinitas baik secara alami maupun antropogen..

\section{Daftar Pustaka}

[1] Alma'ruf..Aplikasi Metode Tahanan Jenis dan Pengukuran Konduktivitas untuk Mendeteksi Intrusi Air Laut Terhadap Lapisan Air Tanah di Daerah Pantai Kuta Kabupaten Lombok Tengah. Tesis. ITB Bandung 1995.

[2] Azhar, Gunawan, Handayani. Penerapan Metode Geolistrik Konfigurasi Schlumberger untuk Penentuan Tahanan Jenis Batubara,Jurusan Geofísika Terapan ITB Bandung. 2004.

[3] Haryanto, A. Aplikasi Metode Resistivitas Menggunakan Geolistrik untuk Monitoring Intrusi Air Laut Skala Model. Skripsi. Semarang: Universitas Negeri Semarang 2011.

[4] Hendrayana, H. Dampak Pemanfaatan Air Tanah. Geological Engineering Departement: Faculty of Engineering Gadjah Mada University. 2002.

[5] Muhammad, Muhammad., Moh Sholichin., Asmaranto, Runi. Studi Tekanan Aliran Airtanah Untuk Konservasi Di Kecamatan Ranomeeto Dan Ranomeeto Barat Kabupaten Konawe Selatan Provinsi Sulawesi Tenggara. Jurnal Teknik Pengairan. 2016.

[6] Moh Sholichin, Panduan Penyelidikan Lapangan Hidrogeologi, UB Press. 2018.

[7] Nisa, K., T. Yulianto., \& S. Widada Aplikasi Metode Geolistrik Tahanan Jenis untuk Menentukan Zona Intrusi Air Laut di Kecamatan Genuk Semarang. Jurnal Ilmu Kelautan dan Perikanan . 2012.

[8] Salam,R. Kajian Aquifer Pantai Pulau Ternate. Jurnal Aplikasi Fisika2011.sdh

[9] Supriyadi, I.H. Pendugan Kandungan Air Tanah dan Air Asin dengan Geolistrick. Lonawartaw,1: 51-67. Jakarta. 1991.

[10] Surdaryo Broto, Rohima Sera Afifah,. Pengolahan Data Geolistrik Dengan Metode Schlumberger. Jakarta. 2018. 